\title{
Experience without using venoveno bypass in adult orthotopic liver transplantation
}

\author{
Dae-Young Kim ${ }^{1}$, In Young Huh ${ }^{1}$, Young Woo Cho ${ }^{1}$, Eun Sun Park ${ }^{1}$, Soon Eun Park ${ }^{1}$, Yang Won Nah², \\ and Chang Ryul Park ${ }^{3}$ \\ Departments of ${ }^{1}$ Anesthesiology and Pain Medicine, ${ }^{2}$ General Surgery, ${ }^{3}$ Thoracic and Cardiovascular Surgery, Ulsan University \\ Hospital, Ulsan, Korea
}

Background: Venoveno bypass (VVB) has been used to achieve hemodynamic stability and decrease the incidence of renal dysfunction. However, VVB has many complications. The purpose of this study is to verify the safety of total clamping of the suprahepatic inferior vena cava (IVC) without VVB during orthotropic liver transplantation (OLT) in terms of anesthetic management.

Methods: Twenty-five patients without preoperative renal dysfunction who underwent primary OLT were enrolled in this study. Hemodynamic data and blood gas measurements were collected 1 hour after incision, 30 minutes after IVC total clamping and 30 minutes after reperfusion. Postoperative laboratory data, including blood urea nitrogen (BUN), creatinine (Cr) and glomerular filtration rate (GFR), were assessed at postoperative day (POD) 0-7, 30, 90, 180 and 1 year.

Results: Mean blood pressure was well maintained during IVC total clamping with infusion of inotropics. There was no case of severe acidosis ( $\mathrm{pH}<7.2)$ during the anhepatic period. The immediate postoperative $\mathrm{Cr}$ and GFR were not significantly different from those of the preoperative values. BUN increased from POD 1 and decreased after POD 6, while Cr increased at POD 90 only.

Conclusions: In patients without preoperative renal dysfunction, when IVC was totally clamped, VVB does not need to be routinely performed to maintain hemodynamics during the anhepatic phase and renal function after OLT. (Korean J Anesthesiol 2011; 60: 19-24)

Key Words: BUN, Creatinine, GFR, IVC total clamp, OLT, VVB.

Received: July 2, 2010. Revised: 1st, July 19, 2010; 2nd, July 22, 2010. Accepted: August 23, 2010.

Corresponding author: In Young Huh, M.D., Department of Anesthesiology and Pain Medicine, Ulsan University Hospital, 290-3, Jeonha 1-dong, Dong-gu, Ulsan 682-714, Korea. Tel: 82-52-250-7248, Fax: 82-52-250-7249, E-mail: inyoung_huh@uuh.ulsan.kr

(c) This is an open-access article distributed under the terms of the Creative Commons Attribution Non-Commercial License (http:// creativecommons.org/licenses/by-nc/3.0/), which permits unrestricted non-commercial use, distribution, and reproduction in any medium, provided the original work is properly cited. 


\section{Introduction}

Orthotopic liver transplantation (OLT) is considered the definitive treatment for end-stage liver disease. The standard technique of OLT causes changes in hemodynamics during the anhepatic phase because of cross clamping of the suprahepatic inferior vena cava (IVC) above the renal vein $[1,2]$. Consequently, interruption of IVC and portal vein flow causes a decrease in cardiac output and arterial blood pressure. This leads to hypoperfused critical organs, and increased systemic vascular resistance. This period is a challenge to anesthesiologists to maintain major organ perfusion.

Venoveno bypass (VVB) has been used to achieve hemodynamic stability and avoid venous congestion, even though controversy still persists over some of its benefits $[3,4]$. Piggyback technique has been proposed as an alternative procedure [5]. This technique allows IVC venous return to the heart, achieving better hemodynamics in the recipient, with decreased renal dysfunction. However, the piggyback technique has been considered in favorable anatomical conditions, and then cross clamping of suprahepatic IVC with or without VVB has been performed in almost cases $[5,6]$. When OLT was performed using total IVC clamp without VVB, hemodynamic instability during the anhepatic phase recovered promptly after reperfusion and renal function was stable after OLT [7].

Over $30 \%$ of patients awaiting OLT have decreased renal function, and preservation of renal function is closely related to mortality and morbidity after OLT [8]. Intraoperative problems, such as hypotension, massive transfusion, pre-existing renal dysfunction, and reduction of GFR during clamping of IVC and portal vein, are major deterioration factors for renal function after OLT $[9,10]$.

The aim of this study was to verify whether suprahepatic IVC total clamp without VVB during OLT had any effect on renal function and hemodynamics.

\section{Materials and Methods}

Thirty adult patients underwent primary OLT between January 2006 and June 2009. We excluded five patients because of preoperative renal dysfunction (preoperative creatinine $>1.5$ $\mathrm{mg} / \mathrm{dl}$ ) and poor records.

All patients were anesthestized in the same manner. General anesthesia was maintained using sevoflurane (0.51.5 vol\%) and $50 \% \mathrm{O}_{2}$-air mixture. Analgesia was provided with continuous infusion of remifentanil $(0.02-0.1 \mu \mathrm{g} / \mathrm{kg} /$ $\mathrm{min}$ ) and muscle relaxation was introduced by vecuronium. We monitored five lead electrocardiogram, invasive arterial pressure in the radial and femoral artery, central venous pressure, pulmonary artery pressure and femoral vein pressure.
We monitored continuous cardiac output via Vigilance (Baxter Healthcare Corp., Irvine, CA, USA). Bispectral index (VISTA ${ }^{\mathrm{TM}}$, Aspect Medical System, USA) and cerebral oximetry (INVOS Oximeter, Somanetics, USA) were also monitored. Patients were transfused using a rapid infusion device with irradiated red blood cells and fresh frozen plasma. Laboratory testing and arterial blood gas analysis were performed at each phase, and abnormal laboratory finding were corrected, such as acidosis, hypocalcemia, and coagulation profiles. Volume replacement and inotropics were routinely supported. All patients had tranexamic acid administration after reperfusion for 3 hours. All patients received standardized immunosuppressions and antibiotics prophylaxis following routine procedures in our facility.

All transplantations were performed by a single experienced liver transplant surgeon and the operation was performed in a similar manner. Suprahepatic IVC was temporarily clamped to test patient tolerance to the total interruption of caval flow. If the patient did not tolerate the suprahepatic IVC interruption, the clamp was released and measured, including infusion of volume and inotropics until mean blood pressure (MBP) was over $60 \mathrm{mmHg}$ at the femoral artery. As soon as the patient tolerated the suprahepatic IVC clamping, the recipient hepatectomy was executed without VVB. If MBP was not over $60 \mathrm{mmHg}$ the VVB would be placed. There was no case to place VVB, and the hemodynamics were well maintained in all cases. The graft was placed orthotopically and after anastomosing the IVC and portal vein, the graft was reperfused.

Recipient parameters included age, gender, Child Pugh score, model of end-stage liver disease (MELD), and creatinine. Hemodynamic data including cardiac output, systemic and pulmonary vascular resistance, right ventricular end diastolic volume index, right and left ventricular stroke work index, and pressures was collected at 1 hour after incision, 30 minutes after IVC total clamping and 30 minutes after reperfusion. Arterial blood gas analysis was performed simultaneously. Intraoperative data such as urine output, inotropic support, and fluid or blood replacement was obtained. Postoperative laboratory results including renal function were assessed by creatinine, blood urea nitrogen (BUN), and GFR, at postoperative day (POD) $0-7,30,90,180$ and 1 year. All parameter are expressed as mean \pm SDs. Statistical analysis was performed using one-way ANOVA and paired t-test. The difference was considered significant when the $P$ value was less than 0.05 .

\section{Results}

OLT with suprahepatic IVC cross clamping without VVB was feasible in all cases. Etiology of cirrhosis was viral except one 
case where cryptogenic liver cirrhosis was observed. Average length of operation from skin incision to closure was 850 minutes (range, 540-1,020 minutes) and the anhepatic phase was 112 minutes (range, 65-180 minutes). Child class A, B, and $\mathrm{C}$ was each 14, 8, and 3 patients (Table 1). Blood transfusion and volume replacement is shown in Table 2. All patients were infused with inotropics during the anhepatic phase to maintain blood pressure. All patients except four were infused with diuretics to maintain urine output. Urine output significantly decreased during the anhepatic phase and was restored after reperfusion.

All hemodynamic parameters significantly decreased during the anhepatic phase except pulmonary vascular resistance, and after reperfusion, restored pre-anhepatic value except MBP (Table 3). After test clamping, the extent of hemodynamic instability was evaluated, and inotropics such as norepinephrine were infused. At the initiation of the

Table 1. Patient Demographic Data

\begin{tabular}{llc}
\hline Sex $(\mathrm{M} / \mathrm{F})$ & & $18 / 7$ \\
Age $(\mathrm{yr})$ & & $51.3 \pm 4.9$ \\
Height $(\mathrm{cm})$ & & $165.6 \pm 8.0$ \\
Weight $(\mathrm{kg})$ & $66.9 \pm 11.1$ \\
Child class & $\mathrm{A}$ & 14 \\
& $\mathrm{~B}$ & 8 \\
MELD score & $\mathrm{C}$ & 3 \\
Underlying disease & Diabetes mellitus & $14.2 \pm 6.5$ \\
& Hypertension & 4 \\
\hline
\end{tabular}

Values are mean \pm SD or numbers. MELD: model of end-stage liver disease. anhepatic phase, if MBP was below $60 \mathrm{mmHg}$, phenylnephrine was additionally infused (5 patients, median $100 \mu \mathrm{g}, 50-500$ $\mu \mathrm{g})$. The heart rate increased at the initiation of IVC total clamp, but gradually decreased and was stable about 30 minutes after IVC clamping. Nine patients experienced post-reperfusion

Table 2. Intraoperative Characteristics

\begin{tabular}{|c|c|}
\hline Crystalloid (ml) & $6,447.1 \pm 1,742.8$ \\
\hline Colloid (5\% albumin, ml) & $2,131 \pm 790.8$ \\
\hline Packed red cell (U) & $9.0 \pm 9.5(0-42)$ \\
\hline Fresh frozen plasma (U) & $15.8 \pm 8.5(7-42)$ \\
\hline Platelet concentrate (U) & $14.5 \pm 6.5(5-25)$ \\
\hline Cryoprecipitate (U) & $6.8 \pm 3.6(0-15)$ \\
\hline Blood loss (ml) & $4,783.3 \pm 4,191.7$ \\
\hline \multicolumn{2}{|l|}{ Creatinine (mg/dl) } \\
\hline Preoperative & $0.9 \pm 0.2$ \\
\hline Highest value after OLT & $1.4 \pm 0.4^{*}$ \\
\hline \multicolumn{2}{|l|}{$\mathrm{GFR}(\mathrm{ml} / \mathrm{min})$} \\
\hline Preoperative & $85.6 \pm 30.0$ \\
\hline Lowest value after OLT & $58.6 \pm 12.5^{*}$ \\
\hline \multicolumn{2}{|l|}{ Urine output (ml/hr) } \\
\hline Pre-anhepatic phase & $123.9 \pm 61.8$ \\
\hline Anhepatic phase & $46.0 \pm 27.5^{*}$ \\
\hline Post-anhepatic phase & $160.4 \pm 59.4$ \\
\hline \multicolumn{2}{|l|}{ Diuretics } \\
\hline Furosemide (mg) & $11.6 \pm 6.0$ (15 patients) \\
\hline Mannitol (gm) & $20.0 \pm 3.8$ (15 patients) \\
\hline \multicolumn{2}{|l|}{ Anhepatic inotropic } \\
\hline Dopamine & 18 \\
\hline Epinephrine & 8 \\
\hline Norepinephrine & 12 \\
\hline Isobide dinitrate & 4 \\
\hline
\end{tabular}

Values are mean \pm SD or numbers. OLT: orthotropic liver transplantation, GFR: glomerular filtration rate. ${ }^{*} \mathrm{P}<0.05$ vs preoperative value.

Table 3. Hemodynamic Change during Liver Transplantation

\begin{tabular}{|c|c|c|c|c|}
\hline & Pre-anhepatic & Anhepatic & Post-anhepatic & $P$ value \\
\hline HR (beats/min) & $75.0 \pm 9.7$ & $96.7 \pm 14.6^{*}$ & $82.0 \pm 9.9^{\dagger}$ & $<0.001$ \\
\hline MBP (mmHg) & $83.3 \pm 8.4$ & $74.5 \pm 8.8^{*}$ & $76.0 \pm 7.0 *$ & $=0.002$ \\
\hline CVP (mmHg) & $7.5 \pm 2.6$ & $5.6 \pm 3.7 *$ & $7.8 \pm 2.3^{\dagger}$ & $=0.042$ \\
\hline Mean PAP (mmHg) & $18.2 \pm 5.3$ & $10.1 \pm 3.8^{*}$ & $20.1 \pm 3.9^{\dagger}$ & $<0.001$ \\
\hline FVP (mmHg) & $9.3 \pm 3.1$ & $31.0 \pm 5.8 *$ & $10.5 \pm 3.1^{\dagger}$ & $<0.001$ \\
\hline $\mathrm{CO}(\mathrm{L} / \mathrm{min})$ & $7.4 \pm 1.7$ & $3.9 \pm 1.1^{*}$ & $8.7 \pm 2.0^{\dagger}$ & $<0.001$ \\
\hline SVR (dynes.s $/ \mathrm{cm}^{5}$ ) & $953.1 \pm 394.8$ & $1,552.4 \pm 543.6^{*}$ & $703.6 \pm 238.9^{\dagger}$ & $<0.001$ \\
\hline PVR (dynes.s $/ \mathrm{cm}^{5}$ ) & $74.6 \pm 34.6$ & $91.5 \pm 37.5$ & $75.1 \pm 27.0$ & $=0.217$ \\
\hline $\mathrm{EF}(\%)$ & $36.7 \pm 8.2$ & $29.1 \pm 9.8 *$ & $38.1 \pm 7.1^{\dagger}$ & $=0.004$ \\
\hline $\mathrm{SV}$ (ml/beat) & $96.3 \pm 21.3$ & $40.3 \pm 15.4^{*}$ & $102.8 \pm 18.1^{\dagger}$ & $<0.001$ \\
\hline RVEDVI (ml) & $165.3 \pm 42.4$ & $93.3 \pm 35.9 *$ & $157.0 \pm 37.2^{\dagger}$ & $<0.001$ \\
\hline LVSWI (g-m/beat $/ \mathrm{m}^{2}$ ) & $54.0 \pm 9.0$ & $23.3 \pm 12.4^{*}$ & $52.3 \pm 7.9^{\dagger}$ & $<0.001$ \\
\hline RVSWI(g-m/beat/m²) & $8.2 \pm 3.7$ & $4.7 \pm 7.6^{*}$ & $7.7 \pm 3.4^{\dagger}$ & $<0.001$ \\
\hline $\mathrm{SvO}_{2}(\%)$ & $88.0 \pm 3.6$ & $75.8 \pm 9.3 *$ & $85.6 \pm 4.5^{\dagger}$ & $<0.001$ \\
\hline BIS & $44.9 \pm 6.0$ & $42.7 \pm 8.6$ & $39.9 \pm 8.2$ & 0.262 \\
\hline $\mathrm{rSO}_{2}$ left (\%) & $66.0 \pm 7.2$ & $58.7 \pm 13.5$ & $66.4 \pm 11.3$ & 0.047 \\
\hline $\mathrm{rSO}_{2}$ right (\%) & $64.7 \pm 8.0$ & $58.3 \pm 11.5$ & $65.2 \pm 8.8$ & 0.139 \\
\hline
\end{tabular}

All values are mean \pm SD. MBP: mean blood pressure, CVP: central venous pressure, PAP: pulmonary artery pressure, FVP: femoral vein pressure, CO: cardiac output, SVR: systemic vascular resistance, PVR: pulmonary vascular resistance, EF: ejection fraction, SV: stroke volume, RVEDVI: right ventricular end diastolic volume index, $\mathrm{LV}$ and $\mathrm{RVSWI}$ : left and right ventricular stroke work index, g-m: gram meter, $\mathrm{SvO}_{2}$ : mixed venous $\mathrm{O}_{2}$ saturation, BIS: bispectral index, $\mathrm{rSO}_{2}$ : regional cerebral $\mathrm{O}_{2}$ saturation. ${ }^{*} \mathrm{P}<0.05$ vs pre-anhepatic value, ${ }^{\dagger} \mathrm{P}<0.05$ vs anhepatic value. 
syndrome and infused epinephrine bolus (median $50 \mu \mathrm{g}$; range, $30-120 \mu \mathrm{g}$ ). Four patients needed more inotropics after reperfusion (norepinephrine 3 patients, epinephrine 1 patient). Conversely, six patients stopped inotropics after reperfusion.

The arterial blood gas analysis results are shown in Table 4. The $\mathrm{pH}$ and $\mathrm{HCO}_{3}{ }^{-}$content significantly decreased at the anhepatic phase and after reperfusion, but base excess, $\mathrm{K}^{+}$, and glucose significantly increased. There was no case of severe acidosis $(\mathrm{pH}<7.2)$ during the anhepatic phase. Acidosis was treated with sodium bicarbonate (median $60 \mathrm{mEq}, 20-120 \mathrm{mEq}$ ) and calcium chloride was infused (median 1,500 mg; range, 600$4,500 \mathrm{mg}$ ) for treatment of hypocalcemia during the anhepatic phase.

BUN significantly increased at POD 1, 2, 3, 4, 5, and 6 compared to the preoperative value. Creatinine also significantly increased at POD 90 compared to preoperative measurements $(0.89 \pm 0.2 \mathrm{mg} / \mathrm{dl}$ vs $1.31 \pm 0.2 \mathrm{mg} / \mathrm{dl}, \mathrm{P}<0.05)$, but creatinine did not increase over $2.0 \mathrm{mg} / \mathrm{dl}$ except in one patient (Fig. 1).

Table 4. Arterial Blood Gas Analysis during Liver Transplantation

\begin{tabular}{|c|c|c|c|c|}
\hline & Pre-anhepatic & Anhepatic & Post-anhepatic & $P$ value \\
\hline $\mathrm{pH}$ & $7.46 \pm 0.04$ & $7.34 \pm 0.06^{*}$ & $7.33 \pm 0.06^{*}$ & $<0.001$ \\
\hline $\mathrm{PaCO}_{2}(\mathrm{mmHg})$ & $35.4 \pm 3.8$ & $36.6 \pm 4.2$ & $40.7 \pm 4.3^{*, \dagger}$ & $<0.001$ \\
\hline $\mathrm{PaO}_{2}(\mathrm{mmHg})$ & $273.6 \pm 74.7$ & $259.6 \pm 72.4$ & $262.7 \pm 54.9$ & 0.782 \\
\hline $\mathrm{HCO}_{3}^{-}(\mathrm{mEq} / \mathrm{L})$ & $25.5 \pm 3.6$ & $19.7 \pm 1.9 *$ & $21.6 \pm 2.6^{*}$ & $<0.001$ \\
\hline Base excess & $2.0 \pm 4.9$ & $-5.1 \pm 3.5^{*}$ & $-2.6 \pm 4.6^{*}$ & $<0.001$ \\
\hline Hematocrit & $32.3 \pm 5.4$ & $30.2 \pm 5.2$ & $25.8 \pm 4.1^{*, \dagger}$ & $<0.001$ \\
\hline $\mathrm{Na}^{+}(\mathrm{mEq} / \mathrm{L})$ & $136.4 \pm 4.2$ & $135.0 \pm 3.6$ & $135.7 \pm 3.6$ & 0.174 \\
\hline $\mathrm{K}^{+}(\mathrm{mEq} / \mathrm{L})$ & $3.5 \pm 0.3$ & $4.0 \pm 0.7^{*}$ & $3.9 \pm 0.7^{*}$ & 0.008 \\
\hline $\mathrm{Ca}^{2+}(\mathrm{mEq} / \mathrm{L})$ & $1.02 \pm 0.08$ & $0.93 \pm 0.13^{*}$ & $1.04 \pm 0.08^{\dagger}$ & 0.002 \\
\hline Glucose (mg/dl) & $117.6 \pm 32.9$ & $153.2 \pm 39.8^{*}$ & $215.5 \pm 48.1^{*, \dagger}$ & $<0.001$ \\
\hline
\end{tabular}

All values are mean \pm SD. ${ }^{*} \mathrm{P}<0.05$ vs pre-anhepatic value, ${ }^{\dagger} \mathrm{P}<0.05$ vs anhepatic value.
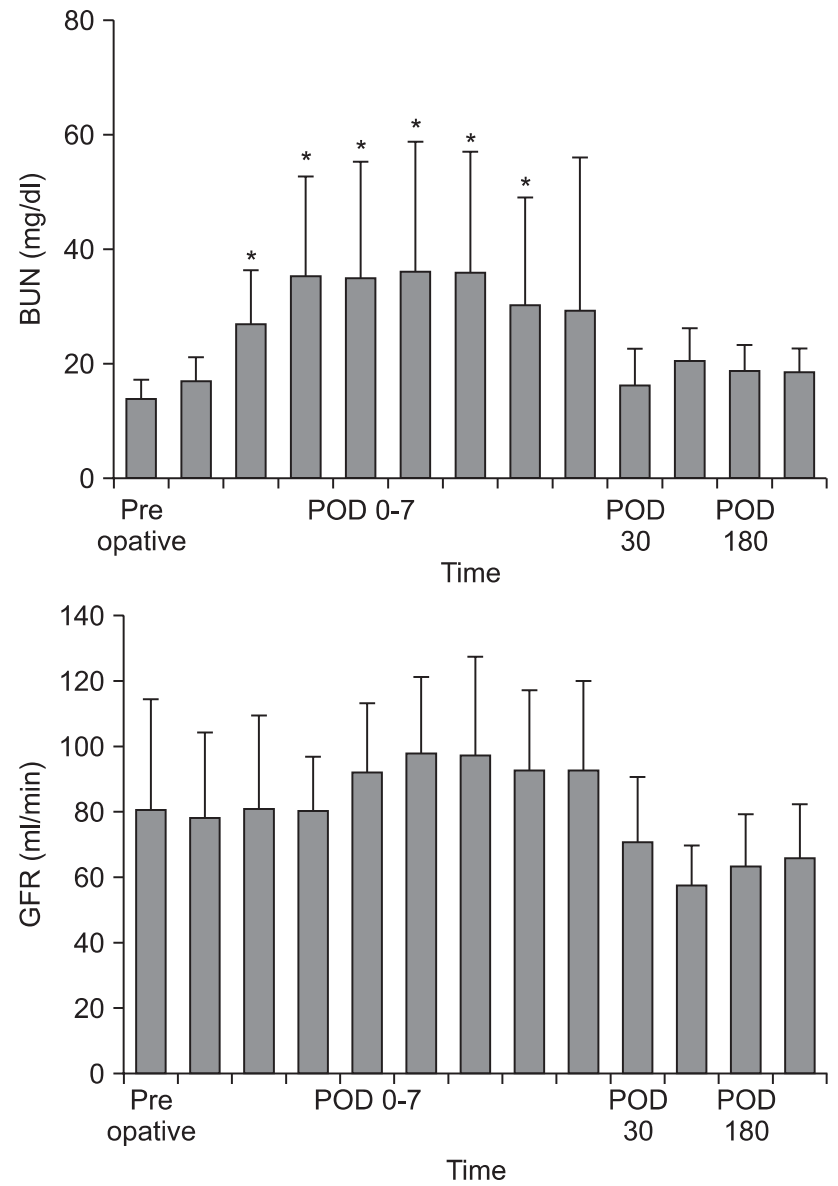

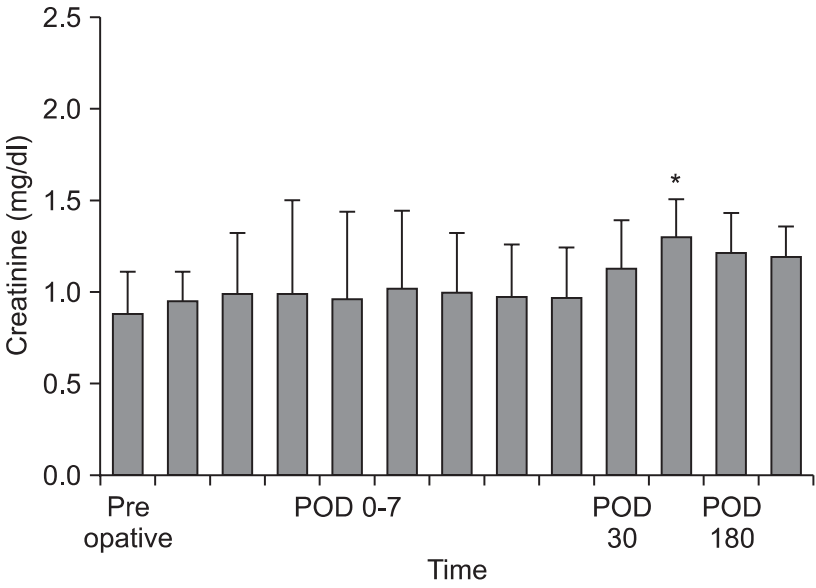

Fig. 1. Change of BUN, creatinine and GFR after orthotropic liver transplantation. Laboratory data was collected at preoperative, immediate postoperative, postoperative $1-7,30,90,180$ days and 1 year. BUN significantly increased at postoperative $1-6$ days and creatinine significantly increased at postoperative 90 days. GFR did not significantly change. BUN: blood urea nitrogen, GFR: glomerular filtration rate. Data presented as mean and SD. $* \mathrm{P}<$ 0.05 vs preoperative value. 
GFR trended to decrease and was lowest at POD 90 but did not show statistical difference compared to the preoperative value. Other laboratory findings were normalized until POD 90 (data not shown). Postoperative mortality occurred in 3 patients until 3 months, due to primary graft failure in one case and rejection in two cases.

\section{Discussion}

We have performed the suprahepatic IVC total clamping method consecutively in 25 OLTs. In this study, suprahepatic IVC total clamping without VVB, even though the anhepatic phase lasted nearly 2 hours, is a safe method if hemodynamics were maintained. During IVC total clamping, inotropics including norepinephrine and volume replacement might be helpful to maintain MBP. In addition, transient decreased renal perfusion pressure does not cause postoperative renal dysfunction.

The standard technique of OLT is when the retrohepatic vena cava is resected with diseased liver [2]. As a consequence the venous return to heart is interrupted during the anhepatic phase because of clamping of both portal and IVC flow, which is associated with a decrease of cardiac output and arterial pressure. This leads to reduction of perfusion pressure in critical organs including the kidney [1]. This problem was relieved with introduction of VVB during OLT. The beneficial effects of VVB include improved hemodynamic stability and reduced renal congestion during clamping of IVC $[1,3,4]$. VVB combined with OLT restores the normal physiology and maintains a sufficient kidney perfusion with lower postoperative dialysis rates [11]. VVB has also decreased the early mortality associated with problems of intraoperative course [3]. However, VVB may be related to complication rates ranging from $10 \%$ to $30 \%$ $[3,9]$. Complications are caused by accidental decannulation, circuit clots, embolic events, prolongation of operation time, vessel injury and coagulopathy $[3,4]$. Massive pulmonary thromboembolism resulting in fatal right heart failure and congestion of transplant liver has been reported [12]. Accordingly, several studies have been reported that show there is no clear advantage for routine use of VVB in OLT, and routine use of VVB appears to be hotly debated across many institutions. Since Calne and Williams [13] reported a technique to preserve the IVC during recipient hepatectomy, surgical techniques have been developed. The piggyback technique, which just tangentially clamped the recipient's suprarenal caval segment, is becoming widely used for OLT and allows to minimizing the hemodynamic disturbances during anhepatic phase and induces lower blood product usage, and lower renal failure $[5,14]$. However, the piggyback procedure can also be difficult due to intensive inflammatory adhesion between liver and
IVC [15]. The surgical technique is also dependent of the preference of surgeon. Some centers decide on the placement of VVB intraoperatively by observing if the patients will hemodynamically tolerate the IVC total clamping [16]. Hence, we want to report our experience to perform OLT without VVB in aspect of anesthetic management and postoperative renal function.

Our institute uses a conventional technique of OLT without VVB. Blood pressure and volume index including cardiac output significantly decreased with high femoral vein pressure during the anhepatic phase, but restored promptly after reperfusion except MBP. During the anhepatic phase, maintenance of blood pressure was initially supported by inotropics including norepinephrine rather than volume replacement, and then systemic vascular resistance (SVR) and heart rate significantly increased and MBP maintained over 70 mmHg. If compensatory increase of SVR was insufficient and MBP was below $60 \mathrm{mmHg}$, phenylnephrine was additionally infused to maintain the MBP to the target. It is critical that lower to normal SVR allows compensatory increase when cardiac output is diminished during the anhepatic phase. Dopamine was infused for renal protection, and epinephrine was also infused for hemodynamic stability. Epinephrine was infused in early experience of our institution, but we routinely infused norepinephrine these days to maintain hemodynamics during anhepatic phase. These drug effects were similar. Isobide dinitrate was infused to treat high pulmonary arterial pressure and resting pulmonary hypertension in preoperative echocardiography. On the other hand, volume replacement was limited, because the patient's volume statues could not be accurately evaluated when the IVC was totally clamped. Central venous pressure has an accepted range from 0 to $5 \mathrm{mmHg}$, if blood pressure is maintained. However, volume was infused a couple of times via rapid infusion system $(300 \mathrm{ml} / \mathrm{min})$ at initial period of the anhepatic phase. Mild acidosis also developed at the anhepatic phase and after reperfusion because of the accumulation of acid metabolites and reduction of perfusion, and bicarbonate was infused due to base excess. There was no patient below $\mathrm{pH}$ 7.2. Calcium chloride was also infused to correct hypocalcemia induced transfusion and to maintain blood pressure at the anhepatic phase. As expected, after IVC declamping, femoral vein pressure decreased abruptly and MBP returned to the pre-anhepatic level. However, MBP still decreased at post-anhepatic phase due to a decrease in SVR, even though it was not significant. MBP was maintained by use of more inotropics and volume replacement. Four patients were infused with more inotropics to maintain MBP.

Urine output was $46 \mathrm{ml} / \mathrm{hr}$ (range, 3-77) and diuretics were infused before suprahepatic IVC was totally clamped. Urine output was also recovered steadily after reperfusion. Wall et al. 
[7] reported that hemodynamic changes observed during the anhepatic phase restored promptly after reperfusion, and renal function remained stable in conventional OLT without VVB. In a comparison study for OLT with or without VVB, VVB is not required to maintain postoperative renal function after OLT when preoperative renal function is positive [17]. Postoperative renal dysfunction is reported up to $70 \%$ and is associated with an independent risk factor of postoperative mortality $[8,18]$. OLT produces major physiologic changes intraoperatively, such as alteration of hemodynamics, activation of renal sympathetic tone, and reduction of renal perfusion $[9,10,19]$. The prevalence of renal failure after OLT is a serious event. One study of 102 liver transplantations revealed $25 \%$ with pre-transplant renal dysfunction and $67 \%$ post-transplant impairment [18]. In cirrhotic patients, serum creatinine frequently failed to elevate above normal even when GFR declined to less than $25 \mathrm{ml} /$ min [20]. Thus creatinine is an insensitive marker of GFR in cirrhotic patients. In this study, GFR tended to steadily increase immediately post operation, but decreased at POD 90 (nonsignificant). GFR decreased $29 \%$ (range, $-50-8 \%$ ) compared to preoperative levels during the entire study period. Early severe renal dysfunction after OLT has been associated with graft failure, infection, immunosuppressants including cyclosporine, and increased mortality [18]. We considered nutrition, medications, and renal vasoconstriction as a reason for delayed decrease of GFR. Renal vasoconstriction was induced by activation of sympathetic tone and derangement of hormones such as prostaglandin and endothelin [21].

Several limitations are presented in this study. The number of patients is small and the methods need to be compared with other procedures such as piggyback. In addition, the study could not assess the record of intensive care treatment during the immediate postoperative period, fluid management and usage of diuretics might be affected postoperative renal function. In addition, characteristics of donor may be affected by the outcome. This study suggests that in patients without preoperative renal dysfunction, as far as hemodynamics is tolerated after IVC total clamp, VVB does not need to be routinely applied to maintain hemodynamic stability during orthotopic liver transplantation and postoperative renal function.

\section{References}

1. Estrin JA, Belani KG, Ascher NL, Lura D, Payne W, Najarian JS. Hemodynamic changes on clamping and unclamping of major vessels during liver transplantation. Transplant Proc 1989; 21: 3500-5.

2. Starzl TE, Marchioro TL, Vonkaulla KN, Hermann G, Brittain RS, Waddell WR. Homotransplantation of the liver in humans. Surg
Gynecol Obstet 1963; 117: 659-76.

3. Shaw BW Jr, Martin DJ, Marquez JM, Kang YG, Bugbee AC Jr, Iwatsuki S, et al. Venous bypass in clinical liver transplantation. Ann Surg 1984; 200: 524-34.

4. Shaw BW Jr, Martin DJ, Marquez JM, Kang YG, Bugbee AC Jr, Iwatsuki S, et al. Advantages of venous bypass during orthotopic transplantation of the liver. Semin Liver Dis 1985; 5: 344-8.

5. Tzakis A, Todo S, Starzl TE. Orthotopic liver transplantation with preservation of the inferior vena cava. Ann Surg 1989; 210: 649-52.

6. Jones R, Hardy KJ, Fletcher DR, Michell I, McNicol PL, Angus PW. Preservation of the inferior vena cava in orthotopic liver transplantation with selective use of veno-venous bypass: the piggy back operation. Transplant Proc 1992; 24: 189-91.

7. Wall WJ, Grant DR, Duff JH, Kutt JL, Ghent CN, Bloch MS. Liver transplantation without venous bypass. Transplantation 1987; 43: 56-61.

8. Gonwa TA, Klintmalm GB, Levy M, Jennings LS, Goldstein RM, Husberg BS. Impact of pretransplant renal function on survival after liver transplantation. Transplantation 1995; 59: 361-5.

9. Aggarwal S. Anesthetic management during liver transplantation. Transplant Proc 1994; 26: 321-4.

10. Steadman RH. Anesthesia for liver transplant surgery. Anesthesiol Clin North America 2004; 22: 687-711.

11. Ozaki CF, Langnas AN, Bynon JS, Pillen TJ, Kangas J, Vogel JE, et al. A percutaneous method for venovenous bypass in liver transplantation. Transplantation 1994; 57: 472-3.

12. Navalgund AA, Kang Y, Sarner JB, Jahr JS, Gieraerts R. Massive pulmonary thromboembolism during liver transplantation. Anesth Analg 1988; 67: 400-2.

13. Calne RY, Williams R. Liver transplantation in man. I. Observations on technique and organization in five cases. Br Med J 1968; 4: 53540.

14. Miyamoto S, Polak WG, Geuken E, Peeters PM, de Jong KP, Porte $\mathrm{RJ}$, et al. Liver transplantation with preservation of the inferior vena cava. A comparison of conventional and piggyback techniques in adults. Clin Transplant 2004; 18: 686-93.

15. Busque S, Esquivel CO, Concepcion W, So SK. Experience with the piggyback technique without caval occlusion in adult orthotopic liver transplantation. Transplantation 1998; 65: 77-82.

16. Johnson MW, Powelson JA, Auchincloss H Jr, Delmonico FL, Cosimi AB. Selective use of veno-venous bypass in orthotopic liver transplantation. Clin Transplant 1996; 10: 181-5.

17. Veroli P, el Hage C, Ecoffey C. Does adult liver transplantation without venovenous bypass result in renal failure? Anesth Analg 1992; 75: 489-94.

18. Rimola A, Gavaler JS, Schade RR, el-Lankany S, Starzl TE, Van Thiel DH. Effects of renal impairment on liver transplantation. Gastroenterology 1987; 93: 148-56.

19. Distant DA, Gonwa TA. The kidney in liver transplantation. J Am Soc Nephrol 1993; 4: 129-36.

20. Papadakis MA, Arieff AI. Unpredictability of clinical evaluation of renal function in cirrhosis. Prospective study. Am J Med 1987; 82: 945-52.

21. Lang F, Tschernko E, Häussinger D. Hepatic regulation of renal function. Exp Physiol 1992; 77: 663-73. 